\title{
Preventing relapse in bipolar disorder
}

\section{Gary Sachs*}

Address: Harvard Medical School, Director, Bipolar Clinic and Research Program, Massachusetts General Hospital, USA

* Corresponding author

from International Society on Brain and Behaviour: 2nd International Congress on Brain and Behaviour

Thessaloniki, Greece. 17-20 November 2005

Published: 28 February 2006

Annals of General Psychiatry 2006, 5(Suppl I):S53 doi:I0.1 I86/I744-859X-5-SI-S53

Bipolar disorder is a life long condition characterized by an irregular pattern of acute episodes separated by periods of full or partial remission. While keeping patients well after a remission is a primary therapeutic goal, relapse rates have remained high despite the wide spread use of lithium. There are now well powered double blind placebo controlled studies demonstrating the efficacy of lithium [1], valproate [2], lamotrigine [3], olanzapine [4-6], and aripiprazole for one or more outcome measure related to prophylaxis.

Understanding the design of these clinical trials can help interpretation of the results for clinical practice. Traditionally the maintenance phase of treatment for patients with mood disorder was conceptualized as therapeutic target separate from the acute and continuation phase. Most randomized clinical trials demonstrating prophylactic treatment benefit, however, use an "enriched design". Rather than randomizing already recovered patients to start study medications, enriched designs begin with subjects who have met criteria for acute response while already exposed to the study drug.

The success of the enriched study design supports continuation of successful acute treatment and/or the integration of potential maintenance phase treatments into the acute phase management plan.

\section{References}

I. Bowden CL, et al: A placebo-controlled 18-month trial of lamotrigine and lithium maintenance treatment in recently manic or hypomanic patients with bipolar I disorder. Arch Gen Psychiatry 2003, 60:392-400.

2. Bowden $\mathrm{CL}$, et al.: A randomized, placebo-controlled I2month trial of divalproex and lithium in treatment of outpatients with bipolar I disorder. Divalproex Maintenance Study Group. Arch Gen Psychiatry 2000, 57:481-489.

3. Calabrese JR, et al:: A placebo-controlled I8-month trial of lamotrigine and lithium maintenance treatment in recently depressed patients with bipolar I disorder. J Clin Psychiatry 2003, 64:1013-1024.

4. Tohen $M$, et al:: Olanzapine versus lithium in the maintenance treatment of bipolar disorder: a 12-month, randomized, double-blind, controlled clinical trial. Am J Psychiatry 2005, 162:128I-1290.

5. Tohen M, et al:: Relapse prevention in bipolar I disorder: I8month comparison of olanzapine plus mood stabiliser v. mood stabiliser alone. BrJ Psychiatry 2004, 184:337-345.

6. Tohen $M$, et al.: Olanzapine versus divalproex sodium for the treatment of acute mania and maintenance of remission: a 47-week study. Am J Psychiatry 2003, 160:1263-127I. 